\title{
Comparision of Radiation-induced Secondary Malignancy Risk Between Intensity Modulated Radiotherapy and Volumetric Modulated Arc Therapy with Simultaneous Integrated Boost in the Treatment of Nasopharyngeal Carcinoma
}

\section{Eş Zamanlı Ek Doz Yöntemi ile Tedavi Edilen Nazofarenks Kanseri Tanılı Hastalarda Radyasyona Bağlı İkincil Kanser Riskinin Belirlenmesi: Yoğunluk Ayarlı Radyoterapi ve Volümetrik Ayarlı Ark Terapi Tekniklerinin Karşılaştırılması}

\author{
Emel Haciislamoğlu \\ Karadeniz Technical University, Faculty of Medicine, Department of Radiation Oncology, Trabzon
}

Dergiye Ulaşma Tarihi: 24/07/2019 Dergiye Kabul Tarihi: 23/08/2019 Doi: 10.5505/aot.2019.49379

\section{ÖZET}

GİRIŞ ve AMAÇ: Çalışmanın amacı, eş zamanlı ek doz (simultaneous integrated boost, SIB) fraksiyon şeması ile yoğunluk ayarlı radyoterapi (intensity-modulated radiotherapy, IMRT) ve volümetrik ayarlı ark terapi (volumetric-modulated arc therapy, VMAT) teknikleri kullanılarak radyoterapi (RT) alan nazofarenks kanseri tanılı hastalarda, organ eşdeğer doz (organ equivalent dose, OED) kavramı kullanılarak, belirlenen organlar için RT'ye bağlı ikincil kanser risklerini hesaplamak ve karşılaştırmaktır.

YÖNTEM ve GEREÇLER: Erken evre nazofarenks kanseri tanılı 5 hastaya ait bilgisayarlı tomografi setleri kullanılarak, IMRT-SIB ve VMAT-SIB tedavi planları oluşturulmuştur. Her bir hasta için üç ayrı PTV (planning target volume, PTV) tanımlanmış; PTV1, PTV2 ve PTV3. PTV’lere sırasıyla 52.8 Gray (Gy), 59.4 Gy ve 69.3 Gy tedavi dozu 33 fraksiyonda verilmiştir. IMRT-SIB ve VMAT-SIB planları oluşturulurken, PTV'ler ve risk altındaki organlar (organs at risk, OARs) için aynı doz hedefleri kullanılmıştır. Planlara ait diferansiyel dozvolüm histogram (dose-volume histogram, DVH) verileri ile Schneider'in "full mechanistic" ve "specific mechanistic sarcoma" modelleri kullanılarak OED değerleri ve ikincil kanser gelişim riskini ifade eden aşırı mutlak risk (excess absolute risk, EAR) değerleri hesaplanmıştır. OED ve EAR'ler beyin sapı, spinal kord, oral kavite, parotis, farenks, submandibular bez, mandibula ve yumuşak doku için hesaplanmıştır.

BULGULAR: IMRT-SIB ve VMAT-SIB teknikleri kullanılarak oluşturulan tedavi planlarının tümünde PTV'ler ve OAR'ler bakımından klinik olarak kabul edilebilir planlar elde edilmiştir. VMAT-SIB tekniği kullanılan planlarda, ikincil kanser riski parotis için istatistiksel olarak anlamlı yüksek bulunmuştur. İkincil kanser riskleri hesaplanan diğer organlar için teknikler arasında fark bulunmamıştır.

TARTIŞMA ve SONUÇ: IMRT-SIB ve VMAT-SIB teknikleri ile RT uygulanan erken evre nazofarenks kanseri tanılı hastalar için tedavi sonrası teorik olarak hesaplanan radyasyona bağlı ikincil kanser riskleri çoğu organ (parotis hariç) için benzerdir. Parotis için ise, VMAT-SIB kullanıldığında ikincil kanser riski yüksektir.

Anahtar Kelimeler: Aşırı mutlak risk, yoğunluk ayarlı radyotreapi, organ eşdeğer doz, ikincil kanser riski, volümetrik ayarlı ark terapi.

ABSTRACT
INTRODUCTION: To compare intensity modulated radiotherapy (IMRT) and volumetric modulated arc therapy (VMAT) with simultaneous integrated boost (SIB) in terms of secondary cancer risk after radiotherapy (RT) of nasopharyngeal cancer using the concept of organ equivalent dose (OED).

METHODS: IMRT-SIB and VMAT-SIB plans were generated with identical objective functions for 5 patients with nasopharyngeal cancer of early stage. Three different planning target volumes (PTVs); PTV1, PTV2 ve 
PTV3 were delineation for each patient and the prescribed doses were 52.8 Gray (Gy), 59.4 Gy and 69.3 Gy delivered in 33 fractions, respectively. Differential dose-volume histograms (DVHs) were used to calculate the OEDs with Schneider's "full mechanistic" and "specific mechanistic sarcoma" dose-response models. Calculations of OED and excess absolute risks (EAR) were applied to the brain stem, spinal cord, oral cavity, parotid, pharynx, mandibular glands, mandible and soft tissue.

RESULTS: Clinically acceptable plans were achieved for all the IMRT-SIB and VMAT-SIB plans. OED-based secondary cancer risk for parotids was significant higher when VMAT-SIB was used. No significant difference was found in terms of the OED and EAR for other organs, including the brain stem, spinal cord, oral cavity, pharynx, mandibular glands, mandible and soft tissue.

DISCUSSION AND CONCLUSION: The most OED-based secondary cancer risks were similar when IMRTSIB and VMAT-SIB were applied. However, the second cancer risk for the parotids was slightly higher when VMAT-SIB was used.

Keywords: Excess absolute risk, intensity-modulated radiotherapy, organ equivalent dose, secondary cancer risk, volumetric-modulated arc therapy.

\section{GİRIŞ}

Nazofarenks kanseri dünyanın birçok yerinde nadir görülen bir malignitedir. Nazofarenks kanserinin küratif tedavisinde ana tedavi yöntemi radyoterapi (RT)'dir ve evre-I hastalık sadece RT ile tedavi edilir (1-3).

Nazofarenks, lokalizasyonu nedeniyle optik kiazma, optik sinirler, temporal loblar, parotis, beyin sapı ve spinal kord gibi birçok organa komşudur ve bu nedenden dolayı nazofarenks RT planları yapılırken kritik organ dozları büyük önem taşımaktadır. Konvansiyonel RT tekniklerinde bu organların tolerans dozları nedeniyle hedef hacimde dozun arttırılması mümkün olmamaktadır. Anatomik olarak karmaşık bir RT alanından oluşan nazofarenks kanserisinin tedavisinde, son 20 yıldır yoğunluk ayarlı RT (intensitymodulated radiotherapy, IMRT) ve volümetrik ayarlı ark terapi (volumetric-modulated arc therapy, VMAT) gibi modern RT teknikleri, lokal kontrol oranlarını arttırma ve aynı zamanda risk altındaki organ (organ at risk, OAR) dozlarını azaltmadaki üstünlükleri nedeni ile yaygın olarak kullanılmaktadır (4-6).

IMRT ve VMAT tekniklerinde eş zamanlı ek doz (simultaneous integrated boost, SIB) yöntemi ile farklı hedef hacimlere aynı anda farklı fraksiyon şemaları uygulanabilir. Primer hedefe 2.1-2.3 Gray (Gy) fraksiyon dozu ile tedavi uygulanırken subklinik boyun bölgesine konvansiyonel fraksiyon dozları veya primer hedefe konvansiyonel fraksiyon dozu ile tedavi uygulanırken subklinik boyuna 1.8 Gy veya daha düşük fraksiyon dozları ile tedavi uygulanabilir $(7,8)$.
Pek çok farklı anatomik bölgenin RT'sinde IMRT ve VMAT tekniklerinin planlanan hedef hacmin (planning target volume, PTV) doz homojenliğini ve konformalitesini arttırdığ 1 ve aynı zamanda OAR dozlarını düşürdüğü gösterilmiş olmasına rağmen, 3-boyutlu konformal RT ile karşılaştırıldıklarında sağlıklı dokulardaki düşük doz hacimlerini artırdıkları da bilinmektedir (9-12). Yoğunluk ayarlı RT teknikleri kullanıldığında düşük doz hacimlerinin artmas1, ikincil kanser riski açısından olumsuz bir etki yaratabilir $(13,14)$.

Göreceli olarak genç hasta grubunu etkilemesi ve sağ-kalım beklentisinin yüksek olmasından dolay1, nazofarenks kanserinin RT'sinde hastaların yaşam kalitesi ve tedavi sonrası radyasyona bağlı ikincil primer kanser gelişme riskine yönelik endişeler ön plana çıkmaktadır. $\mathrm{Bu}$ çalışmanın amacı, organ eşdeğer doz (organ equivalent dose: OED) kavramı kullanılarak, IMRT-SIB ve VMATSIB teknikleri ile RT alan nazofarenks kanseri tanılı hastalarda, belirlenen organlar için RT'ye bağlı ikincil kanser riskini teorik olarak hesaplamak ve karşılaştırmaktır.

\section{GEREÇ ve YÖNTEM}

Hedef hacimler, risk altındaki organlar ve tedavi planlart:

Çalışmamızda, orjinal RT tedavilerinde IMRTSIB tekniği kullanılan, ortalama yaşları 45 olan Evre-1 veya 2 nazofarenks kanseri tanili 5 hastaya ait bilgisayarlı tomografi setleri kullanılmıştır. Her bir hasta için 3 ayrı PTV konturlanmıştır; $\mathrm{PTV}_{1}, \mathrm{PTV}_{2}$ ve $\mathrm{PTV}_{3}$. Magnetik rezonans görüntülemede izlenen gross tümör hacmine $1 \mathrm{~cm}$ marj verilerek 
klinik hedef hacim (clinical target volume, CTV), daha sonra CTV'ye $3 \mathrm{~mm}$ marj verilerek $\mathrm{PTV}_{3}, \mathrm{PTV}_{3}$ 'e nazofarenks, klivusun $1 / 3$ anterioru, nazal kavite ve maksiller sinüsün $1 / 4$ posterioru eklenerek $\mathrm{PTV}_{2}, \mathrm{PTV}_{2}$ 'ye bilateral retrofarengeal, level 2,3,4 ve 5 lenf nodları dahil edilerek $\mathrm{PTV}_{1}$ oluşturulmuştur (Şekil.1). PTV hacimleri oluşturulurken tüm CTV hacimlerine $3 \mathrm{~mm}$ marj verilmiştir. Beyin sap1, spinal kord, parotisler, optik kiazma, optik sinirler, lensler, hipofiz, oral kavite, farenks, submandibular bez, mandibula ve yumuşak doku ise OAR'ler olarak tanımlanmıştır.

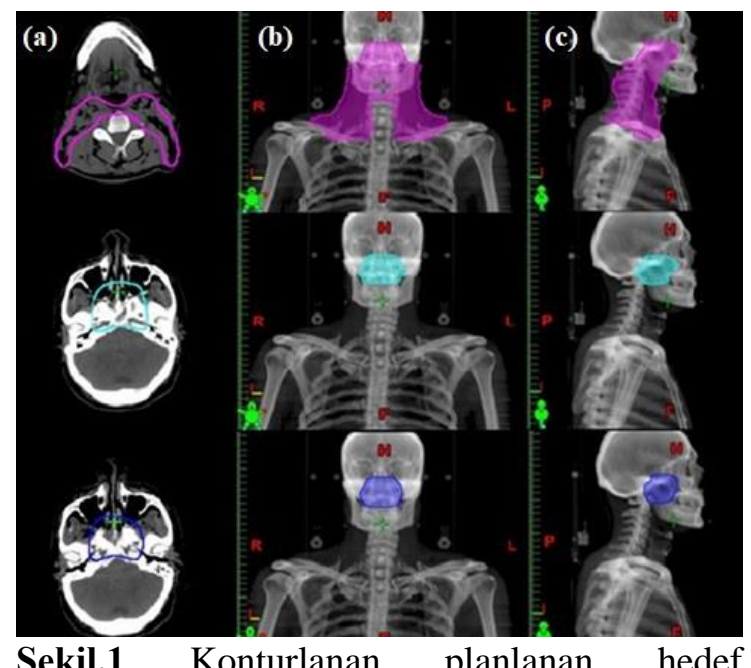
hacimlerin (PTV) (pembe $\mathrm{PTV}_{1}$, açık mavi $\mathrm{PTV}_{2}$ ve koyu mavi $\mathrm{PTV}_{3}$ ) sirasiyla (a) transvers, (b) frontal ve (c) sagital düzlemde gösterimi

Çalışmada kullanılmak üzere her bir hasta için 2 ayrı tedavi planı (IMRT-SIB ve VMAT-SIB) oluşturulmuştur (toplam 10 tedavi planı). Planlar oluşturulurken SIB şeması ile $\mathrm{PTV}_{1}$ 'e 33 fraksiyonda 1.6 Gy dozla toplam $52.80 \mathrm{~Gy}$; $\mathrm{PTV}_{2}$ 'ye 33 fraksiyonda 1.8 Gy dozla toplam 59.40 Gy ve $\mathrm{PTV}_{3}$ 'e 33 fraksiyonda $2.1 \mathrm{~Gy}$ dozla toplam 69.30 Gy tedavi dozu verilmiştir. IMRT-SIB ve VMAT-SIB tedavi planlar1 oluşturulurken P'I'V'ler ve OAR'ler için aynı doz hedefleri uygulanmıştır. PTV'ler için en az \%95'lik hacimlerinin, tedavi dozunun en az \%95'i ile sarılması kriter olarak alınmıştır. Kritik organ dozları belirlenirken Radyoterapi Onkoloji Grubu'nun (Radiation Therapy Oncology Group, RTOG) 0225 numaralı protokolü kullanılmıştır (15).
İkincil kanser riski, beyin sap1, spinal kord, parotis, farenks, oral kavite, submandibular bez, mandibula ve yumuşak doku için hesaplanmıştır. İkincil kanser riski hesaplanan organlardan sadece beyin sapı, spinal kord ve parotis optimizasyon sürecine dahil edilerek doz sınırlaması uygulanmıştır. Farenks, oral kavite, submandibular bez, mandibula ve yumuşak doku için ise herhangi bir doz sınırlaması uygulanmamıştır.

Tüm tedavi planları $6 \mathrm{MV}$ foton enerjisi ve Varian marka Eclipse tedavi planlama sistemi kullanılarak oluşturulmuştur. IMRT-SIB planlarında eşit açı aralıklı toplam 9 dinamik IMRT alanı, VMAT-SIB planlarında ise 2 adet $360^{\circ}$ dinamik ark kullanılmıştır.

\section{İkincil kanser riskinin hesabı:}

Işınlanmış organlardaki ikincil kanser risklerinin tahmini için, Schneider ve ark. tarafindan OED kavramı ortaya konulmuştur $(16,17)$. OED kavramına göre, bir organdaki herhangi iki farklı doz dağılımı, radyasyona bağlı aynı kanser insidansına neden olurlarsa bu iki doz dağılımının eşdeğer olduğu varsayılir (16).

Çalışmamızda, ikincil kanser riski hesaplanacak olan organların OED değerlerinin hesaplanması için organlara ait diferansiyel doz-volüm histogram (dosevolume histogram, DVH) verileri, tedavi planlama sisteminden alınmıştır. Beyin sapı, spinal kord, oral kavite, farenks, parotis ve submandibular bez için OED hesaplamalarında, Schneider'in ikincil kanser gelişiminde kullanılan ve 1 numaralı eşitlik ile verilen, "full mechanistic dose-response model" i kullanılmıştır (18);

$$
\begin{aligned}
& O E D_{\text {mechanistic }}=\frac{1}{V_{T}} \sum_{i} V_{D i} \frac{e^{-\dot{\alpha} D_{i}}}{\dot{\alpha} R}(1-2 R+ \\
& \left.R^{2} e^{\dot{\alpha} D_{i}}-(1-R)^{2} e^{-\frac{\dot{\alpha} R}{1-R} D_{i}}\right)
\end{aligned}
$$

Burada; $V_{T}$ topliam organ hacmi, $V_{D i}$ ise $D_{i}$ dozu ile 1şınlanan organ hacmidir. $\mathrm{R}$ parametresi, fraksiyonlar arasındaki repopülasyonu ve tamir yeteneğini açıklar. Atom bombası sonrası hayatta kalanlar ve $2-40$ Gy'lik dozlarla tek fraksiyonda tedavi edilen Hodgkin hastalarını verilerinin birleştirilmesiyle elde edilen ve her organa özel 
olarak belirlenen $\alpha$ değerleri Tablo 1.'de verilmiștir (18).

Mandibula ve yumuşak doku için radyasyona bağl1 ikincil kanser riski ise, 2 numaralı eşitlik ile verilen, Schneider'in sarkomlar için özel mekanik modeli "specific mechanistic sarcoma dose-response model" ile hesaplanmıştır (18);

$$
\begin{aligned}
& O E D_{\text {sarkom }}=\frac{1}{V_{T}} \sum_{i} V_{D i} \frac{e^{-\dot{\alpha} D_{i}}}{\dot{\alpha} R}(1-2 R+ \\
& \left.R^{2} e^{\dot{\alpha} D_{i}}-\dot{\alpha} R D_{i}-(1-R)^{2} e^{-\frac{\alpha}{1-R} D_{i}}\right)
\end{aligned}
$$

RT sonrası ikincil kanser riski genellikle aşırı mutlak risk (excess absolute risk, EAR) ile tanımlanır (18). EAR, d radyasyon dozuna maruz kalan ve doğal radyasyon dozu dışında herhangi bir bir doza maruz kalmayan kişilerin kanser oranlarındaki mutlak farkı tanımlar (18). EAR değerleri 3 numaralı eşitliğe göre hesaplanmıştır;

$E A R=E A R_{0} \cdot O E D \cdot e^{\left(\gamma e[e-30]+\gamma_{a} \ln \left[\frac{a}{70}\right]\right)}$

Burada, $E A R_{0}$ doz-cevap eğrisinin ilk eğimi, $\gamma$ e ve $\gamma$ a yaş modifikasyon faktörleridir. "e" hastanın ışınlanma yaşını, "a" ise hastanın 1şınlandıktan sonra ulaştığı yaşı temsil eder. Yaş modifikasyonu yapılmadığ 1 sürece $E A R$ formülü 30 yaşında 1şınlanıp $(\mathrm{e}=30), 70$ yaşına ulaşan $(\mathrm{a}=70)$ hasta grubu için geçerlidir. Çalışmamızdaki hastaların yaş ortalaması 45 olduğundan $\mathrm{e}=45$ alınarak yaş modifikasyonu yapılmıştır $(\mathrm{a}=70$ olarak alınmıştır). EAR hesaplamaları için kullanılan parametreler Tablo 1.'de gösterilmektedir.

Tablo 1. Tüm organlar için kullanılan risk

\begin{tabular}{|c|c|c|c|c|c|}
\hline Organlar & $\dot{\alpha}\left(\mathbf{G y}^{-1}\right)$ & $\mathbf{R}$ & $\mathbf{E A R}_{0}$ & $\gamma_{\mathrm{e}}$ & $\gamma_{\mathrm{a}}$ \\
\hline $\begin{array}{l}\text { Beyin Sapı ve } \\
\text { Spinal Kord }\end{array}$ & 0.018 & 0.93 & 0.70 & -0.024 & 2.38 \\
\hline $\begin{array}{l}\text { Oral Kavite ve } \\
\text { Farenks }\end{array}$ & 0.043 & 0.97 & 0.73 & -0.024 & 2.38 \\
\hline $\begin{array}{l}\text { Parotis ve } \\
\text { Submandibular } \\
\text { Bezler }\end{array}$ & 0.087 & 0.23 & 0,73 & -0.024 & 2.38 \\
\hline Mandibula & 0.067 & 0.50 & 0.20 & -0.013 & -0.56 \\
\hline $\begin{array}{l}\text { Yumuşak } \\
\text { Doku }\end{array}$ & 0.060 & 0.50 & 0.60 & -0.013 & -0.56 \\
\hline
\end{tabular}
paremetreleri.
Kisaltmalar: $\quad \boldsymbol{R}$ fraksiyonlar arasinda repopülasyonu ve tamir yeteneği, $\boldsymbol{E A} \boldsymbol{R}_{\boldsymbol{0}}$ doz-cevap eğrisinin ilk eğimi, $\boldsymbol{\gamma} \boldsymbol{e}$ ve $\boldsymbol{\gamma} \boldsymbol{a}$ yaş modifikasyon faktörleri, $\boldsymbol{G} \boldsymbol{y}$ Gray.

\section{Istatistiksel analiz:}

İstatistiksel analizde SPSS (versiyon.18) programı kullanılmıştır. Planların karşılaştırılmasında, eğer parametrik koşullar sağlanıyorsa ANOVA, sağlanmıyorsa KruskalWallis testleri kullanılmıştır. ANOVA testinte varyansların homojenliği Levene testi ile değerlendirilmiştir. Gruplar arasında anlamlı farklılık bulunan durumlarda, ikişerli post-hoc karşılaştırmaları yapılmıştır. p-değerinin 0.05 den küçük olması istatistiksel olarak anlamlı kabul edilmiştir.

\section{BULGULAR}

Ortalama PTV hacimleri $\mathrm{PTV}_{1}$ için $624.96 \mathrm{~cm}^{3}$ $\pm 112.17, \mathrm{PTV}_{2}$ için $177.58 \mathrm{~cm}^{3} \pm 6.96, \mathrm{PTV}_{3}$ için $123.44 \mathrm{~cm}^{3} \pm 27.49$ 'dur. Her iki teknik ile PTV'ler ve OAR'ler bakımından klinik olarak kabul edilebilir planlar elde edilmiştir.

5 hasta için toplam parotisin (sol parotis + sağ parotis) ortalama hacmi $47 \mathrm{~cm}^{3} \pm 13.28$ 'dir. IMRT-SIB planlarında toplam parotisin ortalama dozu 25.78 Gy \pm 88.71 , VMAT-SIB planlarında ise 23.18 Gy \pm 110.18 bulunmuştur. VMAT-SIB planları için DVH'lerden elde edilen parotis ortalama dozları IMRT-SIB planlarından daha düşük olmasına rağmen, hesaplanan OED dozları daha yüksek bulunmuştur (4.06 Gy $\pm 0.06>$ $3.96 \mathrm{~Gy} \pm 0.04)$. Hesaplanan yüksek OED'lere bağlı olarak parotis için ikincil kanser riskinin, VMAT-SIB tekniğinde daha yüksek olduğu ve bu farkın istatistiksel olarak anlamlı olduğu bulunmuştur $(p$-değeri $=0.038)$. Beyin sap1, spinal kord, oral kavite, farenks, submandibular bez, mandibula ve yumuşak doku için teknikler arasında OED ve EAR değerleri bakımından fark yoktur ( $p$-değeri > 0.05). İkincil kanser riski hesaplanan tüm organlar için OED ve EAR değerleri Tablo 2.'de verilmiştir. 
Tablo 2. IMRT-SIB ve VMAT-SIB planlarina ait OED ve EAR değerlerinin karşılaş̧tırılması.

\begin{tabular}{|c|c|c|c|c|}
\hline Organ & Model & IMRT-SIB & VMAT-SIB & $p$-değeri \\
\hline \multirow[t]{2}{*}{ Beyin Sapı } & $\mathrm{OED}^{\mathrm{a}}$ & $18.7 \pm 1.62$ & $21.4 \pm 2.25$ & 0.094 \\
\hline & $\mathrm{EAR}^{\mathrm{b}}$ & $7.58 \pm 0.66$ & $8.70 \pm 0.92$ & 0.095 \\
\hline \multirow[t]{2}{*}{ Spinal Kord } & $\mathrm{OED}^{\mathrm{a}}$ & $15.3 \pm 2.34$ & $16.4 \pm 1.52$ & 0.470 \\
\hline & $\mathrm{EAR}^{\mathrm{b}}$ & $6.21 \pm 0.95$ & $6.65 \pm 0.62$ & 0.469 \\
\hline \multirow[t]{2}{*}{ Oral Kavite } & $\mathrm{OED}^{\mathrm{a}}$ & $17.48 \pm 0.42$ & $17.27 \pm 0.41$ & 0.490 \\
\hline & $\mathrm{EAR}^{\mathrm{b}}$ & $7.40 \pm 0.18$ & $7.31 \pm 0.17$ & 0.505 \\
\hline \multirow[t]{2}{*}{ Farenks } & $\mathrm{OED}^{\mathrm{a}}$ & $20.39 \pm 0.33$ & $20.25 \pm 0.35$ & 0.583 \\
\hline & $\mathrm{EAR}^{\mathrm{b}}$ & $8.63 \pm 0.14$ & $8.58 \pm 0.15$ & 0.595 \\
\hline \multirow[t]{2}{*}{ Parotis } & $\mathrm{OED}^{\mathrm{a}}$ & $3.96 \pm 0.04$ & $4.06 \pm 0.06$ & 0.030 \\
\hline & $\mathrm{EAR}^{\mathrm{b}}$ & $1.68 \pm 0.02$ & $1.72 \pm 0.03$ & $\mathbf{0 . 0 3 8}$ \\
\hline \multirow{2}{*}{$\begin{array}{l}\text { Submandibular } \\
\text { Bez }\end{array}$} & & & & \\
\hline & $\begin{array}{l}\mathrm{OED}^{\mathrm{a}} \\
\mathrm{EAR}^{\mathrm{b}}\end{array}$ & $\begin{array}{l}2.95 \pm 0.09 \\
1.25 \pm 0.04\end{array}$ & $\begin{array}{l}3.07 \pm 0.14 \\
1.30 \pm 0.06\end{array}$ & $\begin{array}{l}0.222 \\
0.239\end{array}$ \\
\hline \multirow[t]{2}{*}{ Mandibula } & $\mathrm{OED}^{\mathrm{a}}$ & $3.87 \pm 0.32$ & $3.33 \pm 0.33$ & 0.054 \\
\hline & $\mathrm{EAR}^{\mathrm{b}}$ & $0.67 \pm 0.05$ & $0.57 \pm 0.06$ & 0.055 \\
\hline \multirow[t]{2}{*}{$\begin{array}{l}\text { Yumuşak } \\
\text { Doku }\end{array}$} & $\mathrm{OED}^{\mathrm{a}}$ & $2.74 \pm 0.11$ & $2.58 \pm 0.17$ & 0.174 \\
\hline & $\mathrm{EAR}^{\mathrm{b}}$ & $1.41 \pm 0.06$ & $1.33 \pm 0.09$ & 0.169 \\
\hline
\end{tabular}

Kisaltmalar: IMRT-SIB eş zamanlı ek doz ile yoğunluk ayarlı radyoterapi, VMAT-SIB es zamanlı ek doz ile volümetrik ayarlı ark terapi, $\boldsymbol{O E D}$ organ eşdeğer doz, $\boldsymbol{E A R}$ aşırı mutlak risk.

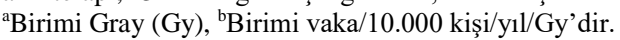

\section{TARTIŞMA}

RT'deki teknolojik gelişmeler, nazofarenks kanserinin tedavisinde sadece tümör kapsanmasını iyileştirmekle kalmayıp, aynı zamanda OAR'leri geleneksel iki-boyutlu RT'ye kıyasla daha iyi koruyan yoğunluk ayarlı tekniklerin kullanılmasina olanak sağlamıştır $(11,12,19,20)$. Yoğunluk ayarlı tekniklerin uygulanabilirliğinde hedef organ hareketliliği çok önemlidir. IMRT veya VMAT gibi yoğunluk ayarlı tedaviler sırasında hedef organdaki hareket ile normal doku bölgelerinde öngörülemeyen yüksek doz alanları veya hedef hacimde düşük doz alanları oluşabilir. Nazofarenks, fizyolojik hareketlerinin k1sitlı olması ve orta hatta yerleşimli olması nedeniyle IMRT veya VMAT teknikleri için oldukça uygundur.

Radyasyona bağlı ikincil kanser riski, RT ile tedavi edilecek kanser hastalarının tedavilerinde uygulanacak olan tekniğe karar verme sürecini etkileyen önemli faktörlerden biridir. Radyasyona bağlı ikincil kanserlerin gelişimine, 1şınlanan alanın hacmi ve dozu, 1şınlanan organ ve doku tipi, kullanılan RT tekniği, RT'nin verildiği yaş, bireysel ve aile kanser öyküsü gibi faktörler katkıda bulunur. IMRT ve VMAT gibi yoğunluk ayarlı RT tekniklerinin, 3-boyutlu konformal RT'ye kıyasla ikincil kanser riskinde potansiyel olarak bir artışa sebep oldukları ile ilgili teorik endişeler ortaya konulmuştur $(13,21,22)$.

Literatürde, IMRT tekniği ile karşılaştırıldığında VMAT'ın hedef hacmi kapsama, doz homojenliği ve OAR'lerde daha iyi koruma sağlama gibi avantajları gösterilmiştir $(23,24)$. Johnston ve ark.'ları nazofarenks ve orofarenks kanserli hastaların VMAT ve IMRT planlarını karşılaştırdıklarında; karşı taraf parotis bezinin maksimum ve ortalama dozu ile $\mathrm{V}_{30}$ değerinin VMAT planlarında daha düşük olduğunu göstermişlerdir (24). Benzer şekilde Lee ve ark.'larının, nazofarenks tedavisinde SIB şeması kullanarak ikincil kanser riski açısından IMRT ve VMAT tekniklerini karşılaştırdıkları çalışmalarında, parotis ortalama dozları VMAT-SIB tekniğinde daha düşük bulunmuştur (25). Çalışmamızın sonuçları, parotisin ortalama dozları bakımından bu iki çalışmayı desteklemektedir.

Çalışmamızda, DVH'lerden elde edilen parotis ortalama dozları VMAT-SIB planlarında IMRT-SIB'e kıyasla daha düşük olmasına rağmen, DVH verileri kullanılarak hesaplanan OED değerleri daha yüksek çıkmıştır. Bu ters ilişki OED dozu hesabının, organ veya dokuda oluşan düşük ve yüksek doz hacimlerinin büyüklüğü ile ilişkili olmasından kaynaklanmaktadır. Yani çalışmamızdan çıkan sonuca göre, IMRT-SIB planları parotis için, daha yüksek ortalama doz nedeniyle akut toksisite bakımından dezavantajlı iken, parotis içindeki düşük ve yüksek doz dağılımları farklılıkları nedeniyle, geç yan etki olarak bilinen ikincil kanser riski bakımından VMATSIB'dan daha avantajlı hale geldiği görülmüştür. Lee ve ark.'nın sonuçları, bizim çalışmamızın aksine ikincil kanser riski 
bakımından parotis için teknikler arasında fark olmadığını göstermiştir (25). Onların sonuçlarına göre sadece oral kavite ve mandibula için VMAT-SIB tekniğinde ikincil kanser riski yükssek çıkmıştır (25).

OAR dozları bakımından VMAT-SIB, IMRTSIB tekniğine kıyasla daha üstün sonuçlar vermesine rağmen, hesaplanan hemen hemen tüm organlar için ikincil kanser risk faktörleri her iki teknik için benzerdir. Hatta daha yüksek ortalama doz değerine rağmen IMRT-SIB tekniğinde parotis için risk faktörü daha düşük bulunmuştur. Sonuç olarak, VMAT-SIB planlarına göre daha yüksek parotis ortalama dozlarına sahip olmasına rağmen, IMRT-SIB planlarının da parotis için tolerans doz değerlerini sağlayabildiği ve erken evre nazofarenk kanseri gibi uzun yaşam beklentisi olan hastaların tedavi tekniğinin kararında hem akut hem de geç yan etkilerin birlikte değerlendirilmesi gerektiği unutulmamalıdır. Ayrıca kullanılan modellerin geçerliliğini test etmek için, farklı tedavi teknikleri ile ikincil kanser riski arasındaki ilişkiyi belirleyen ek çalışmalara ve daha çok sayıda hastanın uzun süreli klinik takibine ihtiyaç vardır.

\section{Çıkar çatışması yoktur.}

\section{REFERANSLAR}

1. Million RR, Cassisi NJ, Mancuso AA, Stringer SP, Mendenhall WM, Parsons JT. Management of the neck for squamous cell carcinoma. In Million RR, Cassisi NJ (editors). Management of Head and Neck Cancer: A Multidisciplinary Approach (2nd ed). Philadelphia; JB Lippincott;1993:75-142.

2. Chan A, Gregoire V, Lefebvre JL, Licitra et al. Nasopharyngeal cancer: EHNS-ESMO-ESTRO Clinical Practice Guidelines for diagnosis, treatment and follow-up. Annals of oncology. 2012; 23: 83-5.

3. Lee YL, Ho CY. Headache as the sole symptom of nasopharyngeal carcinoma and its clinical implications. The Scientific World Journal. 2012;5.

4. Lee TF, Chao PJ, Ting HM, et al. Comparative analysis of SmartArcbased dual arc volumetricmodulated arc radiotherapy (VMAT) versus intensity-modulated radiotherapy (IMRT) for nasopharyngeal carcinoma. J Appl Clin Med Phys. 2011;12(4):3587.

5. EHN Pow, DLW Kwong, AS McMillan et al. Xerostomia and quality of life after intensitymodulated radiotherapy vs. conventional radiotherapy for early-stage nasopharyngeal carcinoma: initial report on a randomized controlled clinical trial. Int J Radiat Oncol Biol Phys. 2006;66(4):981-91.

6. AbdElWahab AS, Mohammed DA, Gaballah AM, Abdallah MM. Three-Dimensional Conformal versus Intensity Modulated Radiation Therapy in Treatment of Nasopharyngeal Carcinoma. The Egyptian Journal of Hospital Medicine. 2018;71 (7):3492-3499.

7. Chao KS, Ozyigit G, Tran BN, Cengiz M, Dempsey JF, Low DA. Patterns of failure in patients receiving definitive and postoperative IMRT for head-andneck cancer. Int J Radiat Oncol Biol Phys. 2003;55(2):312-21.

8. Chao KS, Low DA, Perez CA, Purdy JA. Intensitymodulated radiation therapy in head and neck cancers: The Mallinckrodt experience. Int J Cancer. 2000;90(2):92-103.

9. Johansen S, Cozzi L, Olsen DR. A planning comparison of dose patterns in organs at risk and predicted risk for radiation induced malignancy in the contralateral breast following radiation therapy of primary breast using conventional, IMRT and volumetric modulated arc treatment techniques. Acta Oncol. 2009;48(4):495-503.

10. Fong A, Bromley R, Beat M, Vien D, Dineley J, Morgan G. Dosimetric comparison of intensity modulated radiotherapy techniques and standard wedged tangents for whole breast radiotherapy. J Med Imaging Radiat Oncol. 2009;53(1):92-9.

11. Peng G, Wang T, Yang KY, et al. A prospective, randomized study comparing outcomes and toxicities of intensity-modulated radiotherapy vs. conventional twodimensional radiotherapy for the treatment of nasopharyngeal carcinoma. Radiother Oncol. 2012; 104:286-293.

12. Kam MK, Chau RM, Suen J, Choi PH, Teo PM. Intensitymodulated radiotherapy in nasopharyngeal carcinoma: dosimetric advantage over conventional plans and feasibility of dose escalation. Int J Radiat Oncol Biol Phys. 2003; 56:145-157.

13. Hall EJ, Wuu C. Radiation-induced second cancers: the impact of 3D-CRT and IMRT. Int J Radiat Oncol Biol Phys. 2003;56:83-88.

14. Kry SF, Salehpour M, Followill D, et al. The calculated risk of fatal secondary malignancies from intensity-modulated radiation therapy. Int J Radiat Oncol Biol Phys. 2005;62:1195-1203.

15. Lee NY, Harris J, Garden A, et al. Phase II multiinstitutional study of IMRT chemotherapy for nasopharyngeal carcinoma (RTOG 0225): preliminary results. Int J Radiat Oncol Biol Phys. 2007;69(Suppl.):S13.

16. Schneider U, Zwahlen D, Ross D, Kaser-Hotz B. Estimation of radiation-induced cancer from threedimensional dose distributions: Concept of organ equivalent dose. Int J Radiat Oncol Biol Phys. 2005; 61(5):1510-1515.

17. Schneider U, Walsh L. Cancer risk estimates from the combined Japanese A-bomb and Hodgkin cohorts for doses relevant to radiotherapy. Radiat Environ Biophys. 2008; 47(2):253-263.

18. Schneider U, Sumila M, Robotka J. Site-specific doseresponse relationships for cancer induction from the combined Japanese A-bomb and Hodgkin 
cohorts for doses relevant to radiotherapy. Theor Biol Med Model. 2011; 8:27.

19. Kam MK, Leung SF, Zee B, et al. Prospective randomized study of intensity-modulated radiotherapy on salivary gland function in earlystage nasopharyngeal carcinoma patients. J Clin Oncol. 2007; 25:4873-4879.

20. Pow EH, Kwong DL, McMillan AS, et al. Xerostomia and quality of life after intensitymodulated radiotherapy vs. conventional radiotherapy for earlystage nasopharyngeal carcinoma: initial report on a randomized controlled clinical trial. Int J Radiat Oncol Biol Phys. 2006; 66:981-991.

21. Followill D, Geis P, Boyer A. Estimates of wholebody dose equivalent produced by beam intensity modulated conformal therapy. Int J Radiat Oncol Biol Phys. 1997; 38(3): 667-72.
22. Kry SF, Followill D, White RA, Stovall M, Kuban D A, Salehpour M. Uncertainty of calculated risk estimates for secondary malignancies after radiotherapy. Int J Radiat Oncol Biol Phys. 2007; 68(4):1265-71.

23. Bedford JL. Treatment planning for volumetric modulated arc therapy. Med Phys 2009; 36(11):5128-38.

24. Johnston M, Clifford S, Bromley R, Back M, Oliver L, Eade T. Volumetric-modulated arc therapy in head and neck radiotherapy: a planning comparison using simultaneous integrated boost for nasopharynx and oropharynx carcinoma. Clin Oncol (R Coll Radiol) 2011; 23(8):503-11.

25. Lee HF, Lan JH, Chao PJ, et al. Radiation-induced secondary malignancies for nasopharyngeal carcinoma: a pilot study of patients treated via IMRT or VMAT. Cancer Manag Res. 2018;10:131141. 